\title{
Overin Sklerozan Stromal Tümörü: Olgu Sunumu
}

\author{
Sclerosing Stromal Tumor of the Ovary: A Case Report
}

\section{Gonca Oğurlu PAKAY ${ }^{1}$, Kaan PAKAY ${ }^{1}$, Canan Kabaca KOCAKUŞAK ${ }^{1}$, Ateş KARATEKE ${ }^{1}$, Özden US ${ }^{2}$, Hatice ÖZTÜRKMEN ${ }^{2}$, Ecmel KAYGUSUZ ${ }^{3}$}

1. Zeynep Kamil Kadın ve Çocuk Hastalıkları Eğitim ve Araştırma Hastanesi Kadın Hastalıkları ve Doğum Kliniği, İstanbul

2. Zeynep Kamil Kadın ve Çocuk Hastalıkları Eğitim ve Araştırma Hastanesi Radyoloji Bölümü, İstanbul

3. Zeynep Kamil Kadın ve Çocuk Hastalıkları Eğitim ve Araştırma Hastanesi Patoloji Bölümü, İstanbul

\section{$\ddot{O Z Z E T}$}

Overin sklerozan stromal tümörü (SST), over seks kord tümörleri içinde siniflandırılan ve oldukça nadir görülen benign karakterli bir tümördür. Bu tümörler çoğunlukla 20-40 yaş aralı̆̆ında görülürler, ancak az sayıda olguda postmenopozal dönemde ya da çocukluk döneminde görülebilirler.

13 yaşında anormal uterin kanama ve dismenore yakınması ile başvuran adolesan kızda, alt batın ultrasonografisi (USG) ve pelvik manyetik rezonans görüntülemede (MRG) unilateral heterojen kistik kitle tespit edilmiştir. Bu makalede benign sklerozan stromal tümör olgusunun, görüntüleme, operasyon, histopatolojik özellikleri ve ayırıcı tanısı sunulmuştur.

Anahtar Kelimeler: adolesan; over; sklerozan stromal tümör

\section{ABSTRACT}

Classified among ovarian sex cord tumors, sclerosing stromal tumor (SST) is an extremely rare ovarian malignant tumor which occurs predominantly between the ages of 20 to 40 . However small number of postmenopausal or childhood cases were reported. Lower abdomen USG and pelvic MRI indicated unilateral heterogen cyctic mass in the 13 year old patient who presented to hospital with complaints of dysmenorrhoea and abnormal uterine hemorrage. This article covers imaging, operation, histopathological properties and distinctive diagnosis of the benign sclerosing stromal tumors (SST).

Keywords: adolescent; ovarian; sclerosing stromal tumor

iletişim

Sorumlu Yazar: Gonca Oğurlu PAKAY

Adres: Ümraniye Eğitim Araştırma Hastanesi, Kadın Hastalıkları ve Doğum Kliniği, İstanbul

Tel: +90 (507) 2313238

E-Posta: ogurlu_gonca@hotmail.com

Makale Geliş: 21.12.2015

Makale Kabul: 07.12.2016

DOI: http://dx.doi.org/10.16948/zktipb.272955

\section{GİRIŞ̧}

Sklerozan stromal tümör; ovaryan stromal tümörlerin \%2-6'sını oluşturan, ilk kez 1973'te Chaldvardjian ve Scully tarafindan tanımlanan overin nadir görülen benign tümörlerindendir $(1,2)$. Genellikle unilateraldir; en s1k adet düzensizliği ya da adneksial kitle şikâyeti ile başvuran 2. ve 3. dekadtaki genç kadınlarda gözlenir. Nadiren hormonal olarak aktif olup androjen fazlalığı semptomlarına yol açabilir (3). Tümörün radyolojik görüntüsündeki ve makroskopisindeki solid yapılar malign izlenimi verebilmektedir. Bu nedenle gereksiz radikal cerrahi girişimlere neden olmaktadır (1, $4,5)$. Bu olgu overin seks kord tümörleri içinde oldukça nadir görülen benign over tümörü olması ve kompleks solid kitle ile başvurmuş olması nedeniyle sunulmuştur.

\section{OLGU}

Hastanemiz jinekolojik onkoloji polikliniğine adneksiyel kitle nedeniyle sevk edilen 13 yaşındaki hastanın yaklaşık 3 aydır menometroraji ve pelvik ağrı şikâyeti mevcuttu. Hastanın yapılan fizik muayenesinde sağ pelvik bölgede $9 \mathrm{~cm}$ çapta sert, mobil kitle palpe edildi.Yapılan pelvik ultrasonografide sağ over lojunda $98 \times 75 \times 70 \mathrm{~mm}$ boyutunda heterojen solid kitle izlendi. Pelvik Manyetik Rezonans Görüntülemede, mesane superiorunda batın orta hattan superiora uzanım gösteren düzgün kısmen lobule konturlu, kapsüle, içerisinde yer yer kistik alanlar ile vasküler yapılar izlenen T1 ağırlıklı görüntülerde kas dokusu ile izoiintens, T2 A görüntülerde heterojen-hiperintens, postkontrast serilerde solid alanlarda heterojen yogun boyanan 100x95x65 mm boyutlarında kitle saptanmıştır. Difüzyon ağırlıklı görüntülerde diffüzyon kısitlanması izlenmektedir. Sağ adneksiyel lojda ve sağda belirgin olmak üzere alt kadranlarda barsak ansları arasinda serbest siv1 mevcuttur. Uterus ve sol over doğal görünümdedir. Sağ overe ait olabilecek içinde foliküllerin izlendiği ayrı bir yapı ayırdedilememektedir (Resim 1). 


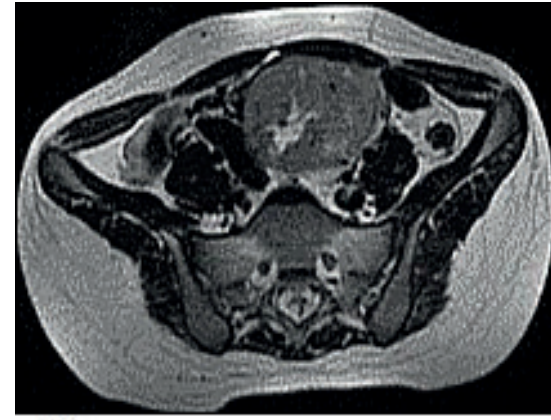

[i]

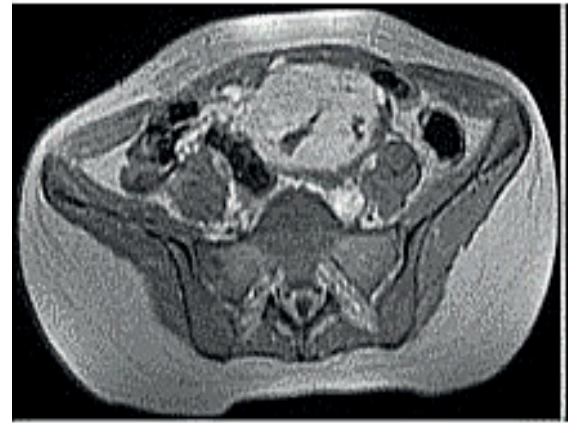

[d]

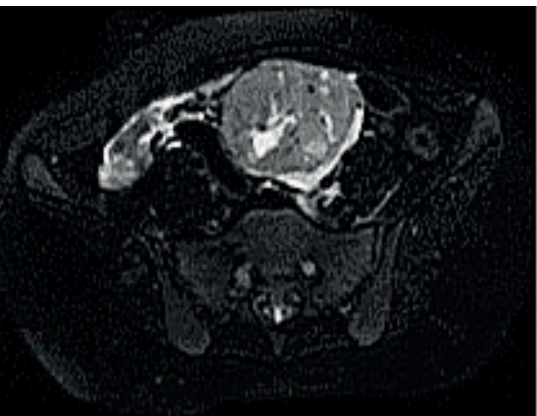

(b)

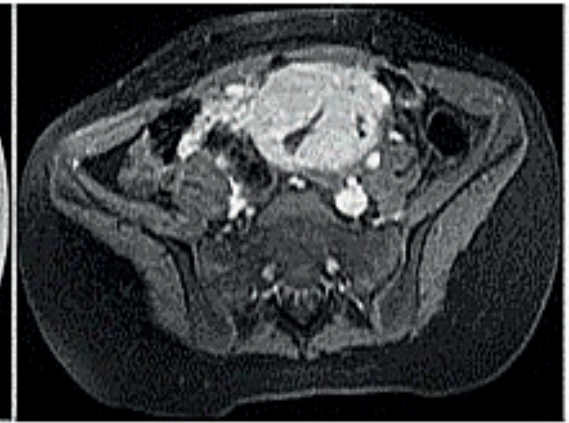

[e]

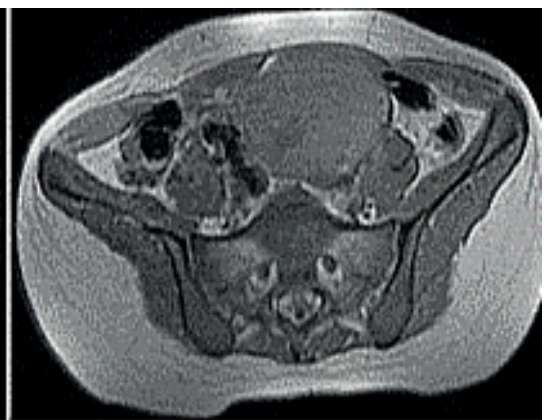

[c]

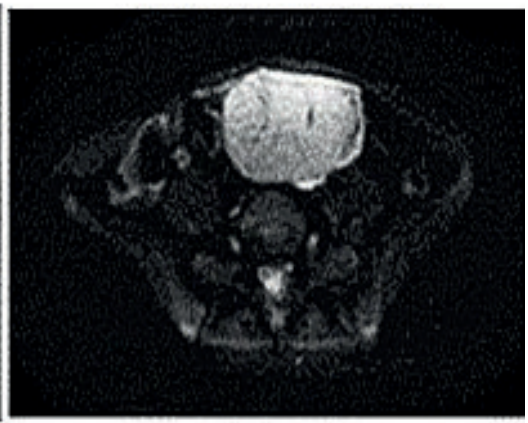

(f)

Resim 1: Hastanın pelvik MR görüntülemesinde; (a) T2 A aksiyal görüntüler, (b) T2 A yağ baskılı aksiyal görüntüler, (c) T1 A aksiyal görüntüler, (d) T1 A postkontrast görüntüler, (e) T1 A yağ baskılı postkontrast görüntüler, (f) Difüzyon ağırıklı görüntüler.

Olgunun biyokimya, follikül uyarıcı hormon, luteinizan hormon, progesteron, estradiol ve testosteron düzeyleri normal sinırlarda idi. Tümör belirteçlerinden alfa-fetoprotein, insan korionik gonadotropini, CA 15-3, CA 19-9, CA-125, inhibin düzeyleri normal sinırlarda idi. Tam kan sayımında hemoglobin düzeyi 7,8 $\mathrm{g} / \mathrm{dL}$, hematoktit \% 24 olan hastaya preoperatif 2 ünite eritrosit süspansiyonu transfüzyonu yapıldı. Yapılan eksplorasyonda sağ over yaklaş1k $10,5 \times 8 \mathrm{~cm}$ boyutunda idi ve içinde yaklaşı $\mathrm{k}$ $9 \times 7 \times 6,5 \mathrm{~cm}$ boyutunda tamami solid, multilobüle, beyaz-sarı renkli, ovoid yapıda, yaygın vasküler görünümde kitle izlendi. Batın sitolojisi alınmasını takiben sağ overden kaynaklanan kitle over dokusu korunarak eksize edildi. Diğer over ve pelvik yüzeyler normal olarak izlendi, batın içi serbest sıvı ya da lenfadenopati saptanmadi. Intraoperatif frozen section sonucu benign kitle gelmesi üzerine operasyona son verildi.

Materyalin patolojik olarak makroskopik değerlendirilmesinde $9 \times 7 \times 6,5 \mathrm{~cm}$ ölçülerinde lobüle kontürlü, düzgün sınırl1, ovoid kitle mevcuttu. Kesit yüzeyi tümüyle solid olup sarımtırak nodüler alanlar bulundurmaktaydı. Lezyonun santraline uyan alanda $6 \mathrm{~cm}$ çapta düzensiz sınırlı kanamalı dejeneratif alanlar görüldü. Mikroskopisinde ise hiposellüler, yoğun kollajenöz veya ödemli stroma içeren alanlar ile daha hipersellüler alanların varlığı dikkati çekti (Resim 2).
Büyük büyütme ile incelendiğinde hücre alanlarının vakuollü stoplazmalı belirgin çekirdekli, yuvarlak-oval şekilli hücreler ile iğsi hücrelerden oluştuğu görüldü. Vakuollü stoplazmalı hücreler, teka hücrelerine benzer özellikler göstermekteydi. Özellikle hipersellüler alanlarda olmak üzere ince duvarlı ektatik, geyik boynuzu şekilli damarlar dikkati çekti.

Mitoz görülmedi. Yapılan immunohistokimyasal incelemede tümör hücreleri; vimentin ve progesteron reseptörü ile pozitif boyanma, Ki-67 ile \% 3-5 boyanma, aktin ve inhibin ile fokal boyanma göstermiştir. Östrojen reseptörü, sitokeratin, desmin ile boyanma görülmemiştir. Morfolojik ve immunohistokimyasal profil birlikte değerlendirildiğinde olgu sklerozan stromal tümör olarak değerlendirilmiştir.

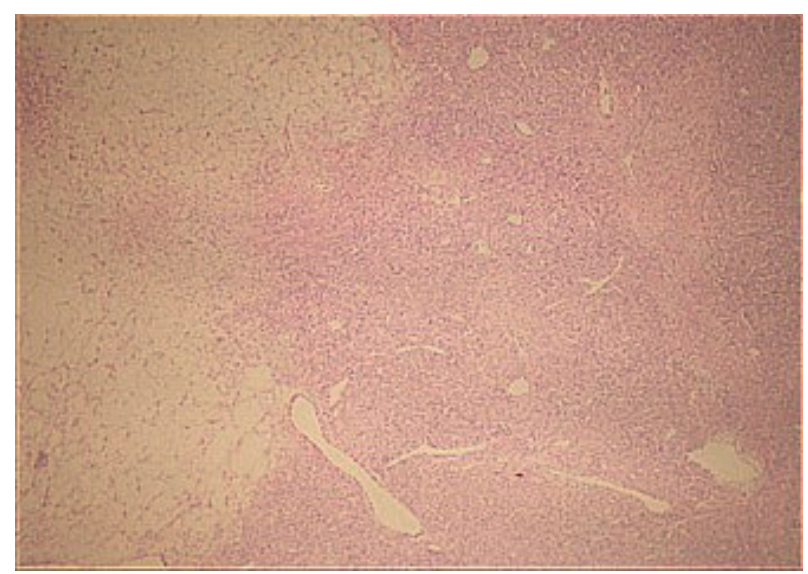

Resim 2: Sklerozan stromal tümörde hiposellüler ve hipersellüler alanlar ile karakteristik damar yapıları (HE x 40). 


\section{TARTIŞMA}

Sklerozan stromal tümör overin diğer seks kord stromal tümörlerinden klinik ve histopatolojik olarak farklı özellikler gösterir. Sklerozan stromal tümörler ilk olarak 1973 yılında Chalvardjian ve Scully tarafından tanımlanmış olup sex kord stromal tümörlerin alt grubu içinde sinıflandırılan ve oldukça nadir görülen benign over tümörleridir $(1,2)$. Literatürde yer alan olguların \%80'inden fazlası 20- 40 yaş aralığındadır; ancak az sayıda olguda postmenopozal dönemde ya da sunulan olguda olduğu gibi adolesan dönemde görülebildiği belirtilmektedir $(6,7)$. Literatürde bildirilen en küçük hasta 7 aylık bir kız çocuğunda puberte prekoks ile seyreden overin sklerozan stromal tümörüdür (8). SST olgularının çoğu hormonal olarak inaktiftir. Adelosanlarda ve kız çocuklarında tümöre bağl1 şikayetler; menstrüel düzensizlik ve karın ağrısı olmasına karşın hasta prematür menarş ya da nadiren asit semptomları ile başvurabilir (9). Bizim olgumuz abdominal ağrı, menometroraji ve anemi semptomları ile başvurdu. Serum hormon değerleri ve tümör markerları normal referans aralığındaydı ve klinik virilizasyon bulguları gözlenmedi.

Preoperatif görüntüleme yöntemleriyle SST tanısinı koymak zordur. USG ile morfolojik analiz yaparak over tümörlerinde maligniteyi belirlemede \%85-97 duyarlıl1k, \%56-95 özgüllük oranları bildirilmiştir (10- 12). Buna göre solid yapı, $3 \mathrm{~mm}$ üzeri papiller uzanıml duvar, vaskülarize mikst-yüksek ekojenite malignite bulgularıdır. Olgumuzun ultrsonografisinde unilateral düzgün sınırlı solid kitle mevcuttu. Malignite için primer MRG kriterleri; solid kitle ya da komponent, $3 \mathrm{~mm}$ 'den kalın duvar, $3 \mathrm{~mm}$ 'den kalın septa ve/veya vejetasyon ve nodülarite içermesi, solid kısımlarda nekroz varlığıdır. Maligniteye eşlik eden kriterler; peritoneal, omental, mesenterik tutulum, asit, lenfadenopati varlığ 1 dır. Bu kriterlerle duyarlılık \%91-100, özgüllük \% 91-92'dir (1216). Olgumuzun pelvik MR bulgularında ise düzgün- kısmen lobule konturlu, kapsüle, içerisinde nekroz ile uyumlu kistik alanlar izlenen, T1 ağırlıklı görüntülerde kas dokusu ile izoiintens, T2 A görüntülerde heterojen - hiperintens, postkontrast serilerde heterojen yoğun boyanan kitle saptandı. Ayrıca batın içi serbest sıvı mevcuttu.

Sklerozan stromal tümörler iki ve üçüncü dekad gençlerde oluşan nadir benign over tümörüdür. MR Görüntülemede T2 A kesitlerde, hiperintens kistik alanlar içeren ve orta- yüksek sinyalli solid heterojen komponentli büyük kitle şeklindedir. Kontrastlı MR Görüntülemede erken periferik ve sentripedal ilerleyen kontrast tutulumu gösterir. Fibromlarda ise kontrast tutulumu pek olmaz ya da hafif erken tutulum olur ve geç dönemde kontrastlanma izlenebilir (16-19). SST'lerde MR görüntüleme bulgular1 sıklıkla T2 A kesitlerde yüksek yoğunluklu stromaya karşı, düşük yoğunluklu nodüler yap1ların gözlendiği pseudolobulasyon şeklindedir (18). Ancak diğer stromal tümörler ve metastatik over tümörlerinin de benzer MR bulgularına neden olabileceğini bildiren çalışmalar bulunmaktadır (20).

Ovarian sklerozan stromal tümörlerinin histopatolojik özellikleri; tümör ödemli ve kollajenöz stroma ile çevrili psödolobül yapısı oluşturan hücresel alanlardan oluşmaktadır. $\mathrm{Bu}$ hücresel alanlarda hemanjioperisitom benzeri damardan zengin bölge de görülebilmektedir (21). Lobül yapıları iki tip hücreden oluşmaktadır; kollajen üreten iğsi hücreler ve teka hücrelerine benzeyen, lipit içeren, vakuollü, eozinofilik stoplazmalı, küçük koyu çekirdekli, belirgin nukleollu hücreler $(2,4,6)$. Bizim olgumuzda da hiper ve hiposellüler alanlardan oluşan psödolobülasyon ve hemanjioperisitamatöz damar yapıları mevcuttu. Mitoz görülmemekle birlikte nadiren mitoz görülen olgu tanımlanmıştır (5). Olgumuzda ise mitoz izlenmemiştir. Bu tümörde literatürde Ki-67 proliferasyon indeksi \% 3-5 civarındadır. İnhibin ve kalretinin immunohistokimyasal boyalarının overin seks kord stromal tümör tanısını desteklemede önemli bir kriter olduğundan söz edilmektedir (1). Yapılan immunohistokimyasal incelemede; inhibin ve kalretininin pozitif olmasi olgumuzun stromal kaynaklı tümör olduğunu desteklemektedir.

Siklıkla 2. ve 3. dekadda görüldüğünden, genelde solid karakterde olup görüntülemede maligniteyi düşündürecek solid kitle varlığı nedeniyle; adölesan ve çocukluk çağındaki genç hastalarda SST ihtimali düşünülerek, ilerdeki fertilite talepleri göz önüne alınarak ve imkân varsa intraoperatif histopatolojik değerlendirme yapılarak mümkün olan en konservatif operasyon tercih edilmelidir.

\section{KAYNAKLAR}

1. Kurt G, Ilhan R, Yavuz E, Tuzlalı S, Iplikçi A. Overin sklerozan stromal tümörleri: altı olgu üzerinde morfolojik ve immunhistokimyasal analiz. Turk J Pathol 2004;20:66-68.

2. Tavassoli FA, Fujii S, Mooney E, et al. Sex cord-stromal tumors In: Tumours of the Breast and Female Genital organs. 5. ed. IARC Press: Lyon; 2003. p. 152-153.

3. Martinelli G, Govoni E, Pileri S, Grigioni FW, Doglioni $C$, Pelusi G. Sclerosing stromal tumor of the ovary. A hormonal, histochemical and ultrastructural study. Virchows Archiv A 1983; 402: 155- 61. 
4. Bildirici K, Illgici D, Peter B. Over sklerozan stromal tümörü (olgu sunumu). Çukurova Üniversitesi Tıp Fakültesi Dergisi 2001; 26(3):147-151.

5. Kaçar Özkara S, Filinte D. Çocukluk ve adolesan dönemlerinde görülen over tümörleri: 42 olguda histopatolojik değerlendirme. Turk J Pathol 2007;23(3):151-159

6. Youm HS, Cha DS, Han KH, Park EY, Hyon NN, Chong Y. A case of huge sclerosing stromal tumor of the ovary weighing $10 \mathrm{~kg}$ in a 71-year-old postmenopausal woman. J Gynecol Oncol 2008; 19(4): 270-

7. He Y, Yang $K X$, Jiang $W$, Wang $D Q$, Li L. Sclerosing stromal tumor of the ovary in a 4-year-old girl with characteristics of an ovarian signet-ring stromal tumor. Pathol Res Pract 2009 Jul 13.

8. Aktaş S,Diniz G, Ortaç R, Ergin M.Sclerosing Stromal Tumor of the Ovary with Precocious Puberty in a Seven Month Old Girl: Case Report. Turkiye Klinikleri J Gynecol Obst 2009;19(2):98-101

9. Kim TH, Lee HH, Hong JA, Park J, Jeon DS, Lee A, et al. Sclerosing stromal tumor in an elderly postmenopausal woman. J Menopausal Med. 2014;20:80-83

10. Reles $A$, Wein $U$, Lichtenegger $W$. Transvaginal color Doppler sonography and conventional sonography in the preoperative assessment of adnexal masses. J Clin Ultrasound 1997; 25: 217-25.

11. Franchi $M$, Beretta P, Ghezzi F, Zanaboni F, Goddi A, Salvatore $S$. Diagnosis of pelvic masses with transabdominal color Doppler, CA 125 and ultrasonography. Acta Obstet Gynecol Scand 1995; 74: 734-9.

12. Pekindil, Gökhan. Over Tümörlerinde Görüntüleme. Trd Sem; 3:108- 126.

13. Jung SE, Lee JM, Rha SE, Byun JY, Jung JI, Hahn ST. $C T$ and MR imaging of ovarian tumors with emphasis on differential diagnosis. Radiographics 2002; 22: 1305-25.
14. Siegelmann ES, Outwater EK. Tissue characterization in the female pelvis by means of MR imaging. Radiology 1999; 212: 5-18.

15. Imaoka I, Wada A, Kaji Y, Hayashi T, Hayashi M, Matsuo $M$, et al. Developing an MR imaging strategy for diagnosis of ovarian masses. Radiographics 2006; 26 : 1431-48.

16. Thomassin-Naggara I, Anbert E, Rockall A, Jalaguier-Coudray A, Rouzier R, Darai E, et al. Adnexal masses: development and preliminary validation of an MR Imaging scoring system. Radiology 2013; 267: 432-43.

17. Stylianidou A, Varras $M$, Akrivis C, Fylaktidou A, Stefanaki S, Antoniou N. Sclerosing stromal tumor of the ovary: a case report and review of the literature. Eur $J$ Gynaecol Oncol. 2001;22:300-304.

18. Lee MS, Cho HC, Lee YH, Hong SR. Ovarian sclerosing stromal tumors: gray scale and color Doppler sonographic findings. Journal of Ultrasound in Medicine 2001; 20:413-7.

19. Kim JY, Jung KJ, Chung DS, Kim OD, Lee JH, Youn SK. Sclerosing stromal tumor of the ovary: MR-pathologic correlation in three cases. Korean Journal of Radiology 2003; 4:194-9.

20. Kawamura N, Kamoi I, Shigyo R. Sclerosing stromal tumor of the ovary. Br J Radiol 1987; 60: 1031- 3.

21. Qureshi A, Raza A, Kayani N. The morphologic and immunohistoochemical spectrum of 16 cases of sclerosing stromal tumor of the ovary. Indian J Pathol Microbiol 2010;53:658-660. http://dx.doi.org/10.4103/03774929.72017 PMid:21045387

22. Young RH, Clement PB. Sex cord-stromal and steroid cell and germ cell tumors of the ovary.In: Mills $S$, editor . Sternberg's Diagnostic Surgical Pathology, Volume II. 5th ed. Lippincott Williams and Wilkins; 2010. p. 2315-2316. 